\title{
English as Foreign Language Student Teachers' Perceptions of the Use of Moodle in a Foundations of Education Course
}

\author{
WAJEHA THABIT AL-ANI \\ Sultan Qaboos University, Oman
}

\begin{abstract}
In order to design an effective e-learning environment, the present study investigated English as Foreign Language (EFL) students' perceptions of the use of Moodle as a course management system in a Foundations of Education (FOE) course at the College of Education. The study also aimed at exploring statistically significant differences between student teachers' perceptions that can be attributed to gender, residence, year in the program, computer skills, and GPA variables. Data were collected from a sample of 60 students using a questionnaire. Findings showed that using Moodle increases students' participation in learning, exchanging ideas and knowledge $(\mu=4.37)$. Over half the total number of students preferred to use chat rooms and forums in computer labs to formal lecture rooms. Findings also showed that there are statistically significant differences between student responses related to year in the program in favor of students in their third and fourth year. With regard to obstacles facing students, the findings showed that most of these obstacles revolve around technical issues and frequent computer errors. Based on these findings, several recommendations were made.
\end{abstract}

\section{INTRODUCTION}

Developing the learning environment tends to be an essential prerequisite for progress in higher education, since computers and other related software have become an important part of students' daily lives. Many universities and educational institutions worldwide have started to invest heavily in e-learning, since it is widely used in three main ways: enhancing classroom teaching, distance education and distributed learning (Bates, 2001). Since the internet was introduced in the Arab World in the mid 1990's, there have been tremendous changes in the education sector in general, and in particular in pedagogies and learning environments. 
The increase of web-based learning technology means teachers and learners are no longer forced to be in the same place at the same time to interact with each other. This idea is supported by Vygotsky's theory on social development, which indicates that social interaction plays a fundamental role in the development of cognition. The core of his theory is focused on collaborative learning environments which afford individual development of meaning through construction and sharing of texts and other artifacts (Smith, Dockrell \& Tomlinson, 1997). In recent years, e-learning has played an important role in enhancing social interaction between students and teachers, and among students themselves. This interaction plays a fundamental role in the development of learner cognition according to Vygotsky. This process was later labeled "social constructivism theory" (Dougiamas \& Taylor, 2003; Smagorinsky, 2007). According to Al-Balooshi (2001) well-managed, welldesigned, well-developed and harmonious E-learning is very crucial for the success of the e-learning experience in the Arab world as a whole. Many educational strategies have been proposed for how best to teach and learn online where real knowledge is gained, where communities of e-learning are developed and where high levels of student satisfaction are generated.

Understanding the vital importance of e-learning requires teachers in higher education to search for the best teaching strategies by implementing technology in learning environments effectively. As a result of the widespread information technology revolution, a shift in the learning paradigm puts learning in the hands of the learner rather than in the hands of the teacher through many multimedia elements such as texts, graphics, audio, videos and animation. Therefore, effective e-learning is considered highly interactive. For example, learners can take a test, receive feedback, discuss ideas, respond to questions, raise issues, take over the instruction and be engaged in online synchronous activities, (e.g. engaged in discussion boards, chatting, writing reflection using Wikis, forums, etc.).

Designing an effective E-learning environment is not easy. It involves many factors beginning with infrastructure, quality of content and assessment, quality of learner support systems, assumptions made by learners and educators about the learning experience itself, and peer support networks for learners and educators (Macnish, Trinidad, Fisher \& Aldridge, 2003).

Information can be easily updated, disseminated and administered (Al-Zafiri, 2001). Al-Hadi (2005) asserts that effective e-learning often helps student to be more self-dependent, 
cooperative, and reflective. These characteristics are considered the core foundation for a student-centered learning environment. Antonenko et al., (2004) pointed out that Moodle learning modules allow instructors to set up an effective learning process that allows students to work individually or in groups in order to maximize student participation and engagement. For example, students can brainstorm possible solutions in chat rooms or discussion forums, then present and compare their solutions to select the best one based on the group discussions. Moodle developers have explicitly stated that the design of the software is grounded in constructivist instructional principles. They focus on the experiences that are best for teaching and assessing the information teachers think that students need to know. Also, they can help each participant in a course to be a teacher as well as a learner in a socially cooperative learning community (Dougiamas \& Taylor, 2003).

An e-learning community is defined as a common place where people learn using group activities to define the problem; encouraging them to decide upon solutions, and to act together to achieve these solutions (Tu \& Corry, 2002). As these communities mature, they gain new knowledge and skills (Mac Neil, 1997). According to the National Center for Educational Statistics, in 20002001, more than $56 \%$ of four-year colleges and universities in the United States offering distance education programs met in person regularly throughout a semester and use online technologies as well. In the College of Education at Sultan Qaboos University (SQU), there are 50 courses out of 393 courses taught in a blended style using Moodle (SQU E-learning, 2007). The transition from face-toface to blended type teaching using Moodle to teach the Foundations of Education (FOE) course, the focus of the present study, began in the Fall of 2007. The purpose of the study was to investigate students' perceptions of the effectiveness of using Moodle in learning a theoretical subject like FOE, which used to be taught in a traditional lecturing mode.

\section{REVIEW OF RELATED LITERATURE}

Using technology in schools and universities has developed rapidly over the last ten years. It provides teachers with many useful tools, and software that can be used to improve the teaching-learning process. In order to investigate the effectiveness of using technology 
such as the Moodle platform, much research has been carried out on its applications and availability.

Recently Moodle has become one of the most popular open-source software applications in education. It supports the socio-constructivist approach to teaching and learning epistemologies within internet-based communities of reflective inquiry (Brandl, 2005; Branzburg, 2005). Moreover, it featured in studies conducted by Perkins and Pfaffman (2006) and Beatty and Ulasewicz (2006) which indicated that as a course management system, Moodle enables the teacher to conveniently improve classroom communication by posting assignments, lesson plans, announcements and course documents. They described how in their experience Moodle improved students' performance by promoting and organizing communication among them, their parents, teachers, administrators and the community.

In 2009, Martin-Blas and Fernandez conducted a study on the use of Moodle as a teaching tool in Physics. They created an online learning community to help both teachers and students have a virtual space in which to share knowledge through different kinds of supervised activities, chats and forums. The findings of their study showed student responses to this initiative as being very good and helpful in reinforcing their skills and knowledge.

With a view to improving self-regulated learning, Vovides, Sanchez-Alonso, Mitropoulou and Nickmans (2007) demonstrated that the adoption of a Moodle system for web-based instruction could help to reach out to potential learners in remote areas where bricks and mortar institutions do not even exist. Also, this system, they argued, can improve student and educator self-regulation abilities, in particular their meta-cognitive skills. Furthermore, Mazza and Botturi (2007) showed that utilizing Moodle in learning provides visualizations of behavioral, cognitive and social data from the course, allowing constant monitoring of student activities, engagement and learning outcomes. In the meantime, Moreno, Gonzalez, Castilla, Gonzalez and Sigue (2007) showed that using the Moodle platform helps in establishing a constructivist and collaborative learning environment especially in teaching computer architecture courses. In addition to that, Fontanin (2008) found that Moodle is especially effective when applied to language learning as it allows one to establish a collaborative environment and to stretch the learning experience over a longer period of time. 
With regard to effectiveness and motivation within a learning culture, Siirak (2008) argued that using Moodle is more highly recommended than providing traditional methods of learning. Meanwhile, Huang and Chuang (2008) found that using an open software like Moodle provided useful feedback for the learner and many human resources to facilitate progress through ill-structured problem-solving situations in a collaborative problem-based learning environment. They also claimed that posting learners' transcripts in Moodle features such as the discussion board or chatting room helps to reduce an instructor's burden.

\section{Effective Learning}

This is concerned with engaging students in a continuous collaborative process of building and reshaping an organized "corpus" of required knowledge by using various learning tools (in this study course, the Moodle system) which encourage the growth of student responsibility, initiative, decision making, and intentional learning. It also attempts to provide students with immediate feedback and reinforcement to increase their achievements and accelerate progress (Grabinger \& Dunlap, 1995).

\section{Modular Object-Oriented Dynamic Learning Environment (Moodle)}

This is a course management system and an open-source software program that educators can use to create quality online instruction. Emerging in 1999, it was the brainchild of Martin Dougiamas. The design of Moodle is based on socio-constructivist pedagogy, which provides a set of tools (chats, forums, reflective journals, wikis, online assignments, quizzes, etc.) that support an inquiry and discovery based approach to online learning. This kind of learning environment allows active collaborative interaction and a multitude of communication patterns such as student-to-student, student-tosubject material, and student-to-teacher (Brandl, 2005).

\section{METHOD AND PROCEDURE}

\section{Purpose of the Study}

The purpose of this study is to investigate EFL student teachers' perceptions of using Moodle in a FOE course at the College of 
Education, Sultan Qaboos University. The study seeks answers to the following questions:

1. What are EFL student teachers' perceptions of the use of Moodle in a Foundations of Education course?

2. Are there any statistically significant differences in student teachers' perceptions that can be attributed to gender, residency, year in the program, student Grade Point Average (GPA) and students' computer skills?

3. What are the obstacles faced by student teachers in using a Moodle system in the FOE course?

\section{Significance of the Study}

The importance of this study stems from many points. The study will attempt to explain some of the characteristics of an effective e-learning environment using a Moodle system. It will also explore the possibility of teaching theoretical courses, like the FOE course in an electronic environment, using the various features that are available in a Moodle system. Finally, it will help in identifying common obstacles faced by students in using Moodle to study the FOE course.

\section{Study Design}

In order to collect the data, a closed-form questionnaire was used to elicit students' responses to the effectiveness of e-learning items which represented the dependent variable. The independent variables are gender (male, female), residency (in-campus, out ofcampus), year in the program (first, second, third and fourth year levels), Grade Point Average GPA: (2.00-2.50, 2.51-3.00, more than 3.00), and Students' Computer Skill SCS (high level, medium level and low level).

The following statistical treatments were used in data analysis: means, standard deviation, t-test and analysis of variance.

\section{Sampling}

A random sampling method was employed and a total of 60 students constituted the intact sample of the present study. These students represented $69.7 \%$ of the total population of 86 students enrolled in the FOE course for the Fall semester of the academic year 2007/2008 in the College of Education, Sultan Qaboos University. Table 1 below shows the demographic data about the participants in the study. 
Table 1. Participants' Demographic Data

\begin{tabular}{llcl}
\hline Variables & Level & Frequency & \% \\
\hline \multirow{2}{*}{ Gender } & Male & 20 & 33.3 \\
& Female & 40 & 66.7 \\
Residency & In-campus & 39 & 65 \\
& Out of-campus & 21 & 35 \\
\multirow{2}{*}{ Year in the program } & First \& Second year & 20 & 33.3 \\
& Third \& Forth year & 40 & 66.7 \\
GPA & $2.00-2.50$ & 23 & 38.3 \\
& $2.51-3.00$ & 24 & 40 \\
Students' computer & More than 3.00 & 13 & 21.7 \\
skills & High level & 17 & 28.3 \\
& Medium level & 43 & 71.7 \\
\hline
\end{tabular}

\section{Research instrument}

The main instrument of the study consisted of three sections. The first section was designed to collect demographic data about the respondents (gender, residency, study year level and knowledge level in using computer). The second section included 31 items representing the perceptions of EFL student teachers' of using Moodle effectively in learning FOE. These items were generated from related literature (Beatty \& Ulasewicz, 2006; Mazza \& Botturi, 2007). The third section included 13 statements representing some common obstacles faced by student teachers in using a Moodle program to learn. A Likert scale was used to measure students' opinion (strongly agree, agree, neutral, disagree, and strongly disagree corresponding to the following numbers $5,4,3,2$, and 1 respectively). The instrument was piloted to establish its reliability. The instrument was also validated through submitting it to a jury judgment. The reliability coefficient was measured by applying Alpha Cronbach and it was found to be 0.92 for all instrument items.

\section{RESULTS AND DISCUSSION}

In addressing the first question of this study, a concern about measuring, from the students' viewpoint, the effectiveness of e-learning when using Moodle in a FOE course, the means and standard deviations of items were calculated. Since the questionnaire 
used had a five-point Likert scale, a theoretical mean of 3.00 (mid point of the scale) was determined as a criterion to judge the mean. It was accordingly apparent that all items were located above the predetermined theoretical mean value. Data are shown in descending order in Table 2.

Table 2. Means and Standard Deviation (SD) of the Students' Responses to each Item of the Questionnaire

\begin{tabular}{ll}
\hline No. Items \\
\hline 1 & Develop students' netiquette communication skills \\
2 & $\begin{array}{l}\text { Increase student participation effectiveness in exchanging } \\
\text { ideas and knowledge }\end{array}$ \\
3 & $\begin{array}{l}\text { Ensure equal opportunity for all students to participate in } \\
\text { electronic discussion dialogue }\end{array}$
\end{tabular}

4 Develop students' skill in browsing the internet

5 Make the subject matter more interesting $\quad 4.12 \quad 0.99$

6 Develop students' typing and editing skills $\quad 4.10 \quad 0.91$

7 Develop students' ability in reflective thinking $\quad 4.10 \quad 0.84$

8 Ensure a learning environment which increases social $\begin{array}{lll}\text { interaction among students during learning process } & 4.08 & 0.87\end{array}$

9 Give fast feedback to evaluate students' achievement $\quad 4.05 \quad 0.90$

10 Ensure a learning environment which helps students to generate $\begin{array}{lll}\text { and develop new ideas } & 4.05 & 0.89\end{array}$

11 Ensure close relations develop among students $\quad 4.03 \quad 0.82$

12 Ensure enough time to develop students' individual skills and abilities

13 Develop students' skill in connecting ideas with their context $\quad 3.98 \quad 0.79$

$\begin{array}{llll}14 & \text { Make it easy for students to follow lectures and extra readings } & 3.97 & 1.01\end{array}$

15 Develop students' ability in "learning by doing" $\quad 3.93 \quad 0.86$

16 Help students facing learning difficulties to cooperate with each other

17 Develop a positive attitude toward subject matter $\quad 3.83 \quad 0.83$

18 Ensure a close relationship exists between students and their teachers

19 Help students to find methods to relate theoretical knowledge to real life situations

20 Increase students' knowledge in their areas of study

21 Increase students' self-confidence and independence $\quad 3.78 \quad 0.93$

22 Develop students' ability to solve problems $\quad 3.77 \quad 0.83$

23 Develop students' appreciation for the values of patience and endurance when doing homework

24 Develop students' skills in making decision related to their learning.

25 Develop students' skills in time management $\quad 3.71 \quad 0.98$

26 Develop students' leadership skills and styles $\quad 3.67 \quad 1.13$

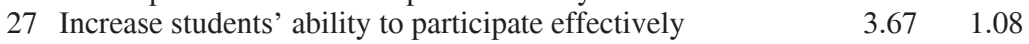


Table 2. (continued)

\begin{tabular}{|c|c|c|}
\hline No. Items & Mean & SD \\
\hline $\begin{array}{l}28 \text { Give students psychological relief while working online } \\
\text { activities }\end{array}$ & 3.58 & 1.09 \\
\hline 29 Develop students' skills in scientific research & 3.52 & 0.99 \\
\hline 30 Increase students' motives toward learning & 3.45 & 1.04 \\
\hline $\begin{array}{l}31 \text { Develop students' ability to understand the relationship } \\
\text { between his/her specialization and other areas of } \\
\text { specialization (interdisciplinary science) }\end{array}$ & 3.27 & 1.02 \\
\hline Total & 3.89 & 0.61 \\
\hline
\end{tabular}

The results in Table 2 show that item 3 on "develop students' netiquette communication skills" is the top rated item with a mean of 4.38. The second top rated item is "increase students' participations effectiveness in exchanging ideas and knowledge" with a mean of 4.37. This is followed by the item on "ensure equal opportunity for all students to participate in electronic in discussion dialog" with a mean of 4.28. These results can be attributed to the fact that students' perspectives regarding the effectiveness of e-learning are concerned with developing their communication skills, exchanging their ideas smoothly, and giving them more opportunities to participate in discussion forums or in chatting, allowing them equal opportunities to state their points of view. Such findings are therefore consistent with the findings of Mazza and Botturi (2007) and Perkins and Pfaffman (2006). Also, the study results show that $53.3 \%$ of the total sample preferred chatting features, while $46.7 \%$ of them preferred Wiki discussion boards.

With regard to the effectiveness of using Moodle, students stated that this system helps them to develop their skills in browsing the internet, showing a mean of 4.17. Besides, it will help them to explore cyber space through various sites, either searching for information or developing their knowledge by sharing it with complementary content experts. This finding is supported by Kester, et al., (2007) who states that Moodle is mostly used to enable the community to share competence and bring learners together for knowledge sharing. Therefore, this makes the subject matter more interesting to students as shown in item five with a mean of 4.12. This finding is also supported by Perkine \& Pfaffman (2006) who showed the usefulness of using Moodle in teaching by giving a description of how Moodle improved and enhanced student's performance by promoting and organizing communication and interaction among them.

Item 6 on "students' skills in editing and typing their work" has a mean of 4.10. This shows the effectiveness of using Moodle in helping students to develop their fundamental skills needed for 
chatting and reflective thinking (to be more flexible and adopt a personalized way of learning). The study result showed that item 7 "develop student ability in reflective thinking" with a mean of 4.10 matched to a great extent the research finding of Antonenko et al., (2004) and Perkins and Pfaffman (2006) who suggested that Moodle supported the pedagogy of a learning environment that is interactive, collaborative, and reflective. It allows the instructor to ask students to write their reflections regarding a particular topic by giving them enough time in to edit and refine their reflections. This activity promotes self-assessment, critical thinking and metacognition. Moreover, using Moodle in learning can help to reduce distractions and roadblocks to learning, and improve communication with fellow students as well.

It is also noteworthy to mention the lowest average mean of responses in the distribution, as this can help in improving the level of effectiveness in using the Moodle system as a whole. Results showed that item 30 "Increase students motivation toward learning" has a mean of 3.45 followed by item 31 "develop student ability to understand the relationship between his/her specialization and other specialization (interdisciplinary science)" with a mean of 3.27. These findings might be related to the fact that most students do not realize the impact of using Moodle on their achievement. Also, students are still unaware of the effect of e-learning on developing their abilities and understanding the relationships among various types of study fields and disciplines.

In response to the second question that is aimed at investigating the statistical differences among students' attitude toward the effectiveness of using Moodle in studying FOE, various variables which include gender, residency, study year and level of knowledge in using computer, were tested using t-test and One Way Analysis of Variance (ANOVA). Table 3 shows the means of all the mentioned variables and the result of the t-test analysis.

Table 3. Result of t-test on Study Variables

\begin{tabular}{llcccc}
\hline Variables & Type & Means & SD & $\begin{array}{c}\text { t- test } \\
\text { value }\end{array}$ & $\begin{array}{c}\text { 2-tailed } \\
\text { significance }\end{array}$ \\
\hline Gender & Male & 3.83 & 0.45 & 0.509 & 0.613 \\
& Female & 3.92 & 0.68 & & \\
Residency & In campus & 3.91 & 0.68 & 0.355 & 0.724 \\
Year in the & Out of campus & 3.85 & 0.45 & & \\
program & First \&second & 3.55 & 0.75 & 3.304 & $0.004^{*}$ \\
Students' & Third \& fourth & 4.06 & 0.45 & & \\
computer skills & High level & 3.99 & 0.59 & 0.840 & 0.404 \\
\hline
\end{tabular}

*Significant difference at $(\alpha=0.05)$ 
Table 3 shows that there is a significant difference $(\alpha=0.05)$ due to the "year in the program" variable in favor of third and fourth year levels with a mean of 4.06 compared with first and second year levels with the mean of 3.55. However, there are no significant differences due to gender, residency and students' computer skills related to the effectiveness of using Moodle in studying FOE.

The results of the ANOVA test analysis are presented in Table 4.

Table 4. Result of ANOVA test on GPA and effectiveness of using Moodle

\begin{tabular}{lccccc}
\hline Levels & $\begin{array}{c}\text { Sum } \\
\text { square }\end{array}$ & $\begin{array}{c}\text { Degree of } \\
\text { freedom }\end{array}$ & Mean square & F value & $\begin{array}{c}\text { 2 tailed } \\
\text { significance }\end{array}$ \\
\hline Between & 1.539 & 2 & 0.770 & 2.146 & 0.126 \\
Within & 20.442 & 57 & 0.359 & & \\
Total & 21.981 & 59 & & & \\
\hline
\end{tabular}

As shown in Table 4, there are no significant differences $(\alpha=$ 0.05 ) among student responses on the item "GPA and effectiveness of using Moodle in studying FOE course."

From the findings shown in Tables 3 and 4, we can conclude that the responses of third and fourth level showed a higher value for the effectiveness of using Moodle. This might be due to the fact that most of the students have studied more courses in teaching methods and instruction as part of their study plan. Also, they have been introduced to many electronic types of learning environment, which made them better able to value the extent of the characteristics of e-learning environment effectiveness compared with first and second year students.

Looking at the gender variable, the t-test findings revealed that there are no significant differences among students' point of views. This finding is consistent with Shatnawee (2007) and Rawashda \& Al-Mumany (2004) who state that there are no significant differences between males and females in their evaluation of the level of effectiveness in using technology and computer-based learning. These studies show the same level of effectiveness for both genders as there is equal opportunity to participate in learning activities.

The third question of this study is aimed at identifying obstacles facing students when using Moodle in learning FOE, and the findings are as shown in Table 5. 
Table 5. Obstacles Facing Students in e-learning Environment using a Moodle Program

\begin{tabular}{llc}
\hline No. & Obstacles & \% \\
\hline 1. & Frequent breakdowns of computers in university labs & 66.7 \\
2. I do not have enough time to work in computer lab & 63.3 \\
3. & Frequent shutdowns of internet connection & 56.7 \\
4. I face difficulties in studying at a computer monitor & 55.0 \\
5. I feel worried about having online quizzes & 53.3 \\
6. I do not have my own personal computer & 51.7 \\
7. I face difficulties in getting to use a computer in the university & 48.3 \\
& \\
8. lab. & \\
& & \\
9. & network connections to the course site through the university & 41.7 \\
10. There is no technical advisor who can guide me to use the & \\
& & \\
11. I having limited knowledge about the Moodle program & 20.0 \\
12. I do not have typing and editing skills & 16.7 \\
13. I do not have skills in using a computer & 8.3 \\
\hline
\end{tabular}

The list in Table 5 shows that the percentage range of the first six obstacles facing student in e-learning is between $66.7 \%$ $51.7 \%$. Most of these are related to technical difficulties that are faced by students in e-learning. Students complained that they do not have enough time to enter computer laboratories and carry out their activities. This indicates lack of time management among them (63.3\%). Also, students lack some basic skills that will enable them to solve simple technical problems. In addition they are still facing some difficulties in changing their learning style to become an e-learner $(55 \%)$. They need more practice to accommodate this type of learning. Also, the frequent breakdowns of university computers $(66.7 \%)$ make them feel frustrated when trying to complete their assignments.

In order to move smoothly to an e-learning environment, there is a need for cooperative efforts in various aspects: ensuring first, a strong infrastructure that begins with establishing efficient computer laboratories equipped with high quality computer sets and technicians who are willing to help students in dealing with any technical problems. Sambrook (2003) reminds us that an e-learning environment is created in order to reduce some difficulties or obstacles facing learners in traditional face-to-face learning environment. Finally, the transition to an e-learning environment needs to move 
quickly. There is the urgent need to spread the etiquettes of this type of learning environment among students by establishing an e-learner oriented newsletter for students so as to show them the benefits and usefulness of e-learning in enhancing their leaning skills and fulfilling their pedagogical needs.

\section{RECOMMENDATIONS AND SUGGESTIONS}

This study is aimed at investigating the effectiveness of using Moodle in studying a FOE course; it is a theoretical course which helps students to customize the learning materials according to their own needs and to enable them to have more control over their learning process. In this way, they can better understand the course materials. The effectiveness of using Moodle has given students a great opportunity to be more self-directed, and learner-centered. It is undertaken anywhere from classrooms to homes since it occurs at one's own space and place.

Based on the above results, the study made recommendations on how to design a short orientation training course or workshop by the Center of Educational Technology for students at the SQU. A Moodle system was proposed in order to develop student skills and abilities in using an appropriate technology tool in learning. The study also suggested the need to develop students' positive attitudes toward e-learning by continuously monitoring them throughout the FOE course. It was also recommended that in order to popularize information technology netiquette among students at the College of Education, a one-credit hour course on "ethics and values of e-learning communities", be added to their course plan so as to introduce students to e-learning community ethics and values. Finally, it was strongly recommended that there was an urgent need to increase the number of computer laboratories at SQU so as to expeditiously accommodate the increasing number of students who require internet services.

\section{REFERENCES}

Al-Balooshi, F. M. (2001). Creating e-learning communities: Effective strategies for Arab World. Proceeding of Educational Technology in Higher Education Symposium. Oman: Sultan Qaboos University, Center of Educational Technology. 
Al-Zafiri, F. (2001). Analysis of the impact of e-learning technologies on training and learning process. Proceeding of Educational Technology in Higher Education Symposium, Oman: Sultan Qaboos University, Center of Educational Technology.

Al-Hadi, Muhammed M. (2005). Electronic Learning through Internet. Cairo: Lebanon and Egyptian Publisher.

Antonenko, P., Toy, S., \& Niederhauser, D. (2004). Modular objectoriented dynamic learning environment: What open source has to Offer, Association for Educational communications and Technology, 27 ${ }^{\text {th }}$, Chicago, IL, October, 19-23. (ERIC Document Reproduction Service No. ED 485088).

Bates, T. (2001). National strategies for e-learning in postsecondary education and training. Paris: The International Institute for Educational Planning Imprimerie Alenconnaise Publisher.

Beatty, B., \& Ulasewicz, C. (2006). Faculty perception on moving from blackboard to the Moodle learning management system, TechTrends: Linking Research and Practice to Improve Learning, 50(4), 36-45.

Brandl, K. (2005). Are you ready to "Moodle"?. Language Learning \& Technology, 9(2), 16-23.

Branzburg, J. (2005). How to use the Moodle Course Management System, Technology \& Learning, 26(1). (ERIC Document Reproduction Service No. EJ 726817).

Dougiamas, M., \& Taylor, P. C. (2003). MOODLE: Using learning communities to create and open sources course management system. Proceeding of the EDMEDIA 2003 Conference, Honolulu, Hawaii.

Fontanin, M. (2008). Developing an English course for in-service librarians: The advantages of blended learning. Library Management, 29(8-9), 777-788.

Grabinger, R. C., \& Dunlap, J. C. (1995). Rich environment for active learning: A definition. Open \& Distance Education and e-Learning, 3(2), 5-34.

Huang, C. J., Chuang, Y. T. (2008). Supporting the development of collaborative problem-based learning environment with an intelligent diagnosis tool. Expert System with Applications, 35(3), 622-631.

Kester, L., VanRosmalen, P., Brouns, F., Kone, M., \& Koper, R. (2007). Matchmaking in learning networks: Bringing learner together for knowledge sharing. Interactive Learning Environment, 15(2), 117-126. 
MacNeil, T. (1997). Assessing the gap between community development practice and regional development policy. In B. Wharf \& M. Claguet (Eds.), Community organizing Canadian experiences (pp. 149-163). Toronto: Oxford University Press.

Macnish J., Trinidad S., Fisher D., \& Aldridge J (2003). The online learning environment of a technology-rich secondary college. Paper Presented at the Annual Meeting of American Educational Research Association, Chicago, IL.

Martin-Blas, T., Fernandez, S. A. (2009). The role of new technologies in the learning process: Moodle as a teaching tool in Physics. Computer \& Education, 52(1), 35-44.

Mazza, R., \& Botturi, L. (2007). Monitoring an online course with the GISMO tool: A case study. Journal of Interactive Learning Research, 18(2), 251-265.

Moreno, L., Gonzalez, C., Castilla, I., Gonzalez, E. J., \& Sigue, J. (2007). Use of constructivism and collaborative teaching in an ILP processors course, IEEE Transactions on Education, 50(2), 101-111.

Perkins, M., \& Pfaffman, J. (2006). Using a course management system to improve classroom communication, Science Teacher, 73(7), 33-37. (ERIC Document Reproduction Service No. EJ 758663).

Rawashda, E., \& Al-Mumany K. (2004). The effect of computer learning based learning program in teaching ten grade student some chemical concepts and the degree of mastering them. Abhath Al-Yarmouk Journal, 20 (3A), 1337-1503.

Sambrook, S. (2003). E-learning in small organization. Education and Learning, 45(8/9), 506-516.

Smith, L., Dockrell, F., \& Tomlinson, P. (1997). Piaget, vygotsky and beyond, simultaneously. USA \& Canada: Routledge Publisher.

Shatnawee, N. M. (2007). Student perception in using informational technology in higher education and its relation to some variables in Yarmouk University. Journal of Educational Science, (12), 234-273.

Siirak, V. (2008). Moodle e-learning environment: An effective tool for a development of learning culture. Proceedings of the Institution of Chemical Engineering Symposium Series, Estonia: Tallinn University of Technology, Department of Working Environment and Safety. 
Smagorinsky, P. (2007). Vygotsky and the social dynamics of classrooms. English Journal, 97(2), 61-66.

SQU E-learning. Course categories. Retrieved December 27, 2007, from (http://squ.edu.om/course/index.php)

Tu, C., \& Corry, M. (2002). E-learning community. The Quarterly Review of Distance Education, 3(2), 207-218.

Vovides, Y., Sanchez-Alonso, S., Mitropoulou, V., \& Nickmans, G. (2007). The use of e-learning course management system to support learning strategies and to improve self-regulated learning. Educational Research Review, 2(1), 64-74. 